\title{
EL MEME EN INTERNET COMO TEXTO DIGITAL: CARACTERIZACIÓN Y USOS SOCIALES EN PROCESOS ELECTORALES
}

\author{
THE INTERNET MEME AS A DIGITAL TEXT: CHARACTERIZATION AND SOCIAL \\ USES IN ELECTORAL PROCESSES
}

\author{
Gabriel Pérez Salazar \\ Universidad Autónoma de Coahuila, México \\ gabrielperezsalazar@gmail.com
}

\begin{abstract}
RESUMEN: El meme en Internet puede ser entendido como un texto digital que implica no solo complejos sistemas de referencias, sino también extensas posibilidades expresivas. Se trata de un recurso de enunciación que recientemente ha adquirido mayor relevancia social, en buena medida, a partir de las características sociotécnicas de las plataformas sociodigitales en las que circulan ampliamente, entre las que destacan Facebook, Twitter, entre otras. A pesar de que se trata de unidades de sentido dadas por distintos tipos de signos (pueden ser tanto cadenas de caracteres como imágenes en movimiento o estáticas), haremos énfasis en estas últimas, en función del corpus de análisis recopilado. A partir de una observación de tipo cualitativo, durante el proceso electoral para la elección presidencial en México (que tuvo lugar entre diciembre de 2017 y julio de 2018), se registraron 900 memes a través de los cuales es posible identificar diversos tipos de expresiones, algunas de las cuales pueden ser ubicadas en cercanía a prácticas políticas. El objetivo central del trabajo que se propone es reflexionar sobre la naturaleza del meme como texto, así como las posibilidades que brinda para observar las dinámicas que uso y reinterpretación de estos signos de naturaleza digital, a partir de un contexto electoral en el que los usuarios participaron generando, compartiendo y modificando este tipo de unidades culturales.
\end{abstract}

PALABRAS CLAVE: memes en Internet; texto; usos sociales de la tecnología; elecciones.

ABSTRACT: Internet memes can be understood as digital texts that involve not only complex systems of references, but also extensive expressive possibilities. It is an enunciation resource that has recently acquired greater social relevance, largely from the sociotechnical characteristics of the social network sites in which they circulate widely, among which Facebook, Twitter and others stand out. Although these are units of meaning given by different types of signs (they can be both strings of characters as moving or static images), we will emphasize the last ones, depending on the corpus of analysis collected. From a qualitative observation, during the electoral process for the presidential election in Mexico (which took place between December 2017 and July 2018), 900 memes were registered through which it is possible to identify various types of expressions, some of which can be located in close proximity to political practices. The main objective of the proposed work is to reflect on the nature of the meme as a text, as well as the possibilities it offers to observe the dynamics of use and reinterpretation of these signs of a digital nature, from an electoral context in which users participated generating, sharing and modifying this type of cultural units. 
KEYWORDS: internet memes; text; social uses of technology; elections.

\section{Introducción}

Para quienes son usuarios de Internet y, en especial, de redes sociodigitales como Facebook, Twitter, Instagram, Pinterest y WhatsApp; durante los últimos años ha sido notable la creciente circulación de imágenes y videos virales. Se trata de un fenómeno que ha despertado el interés de especialistas en una amplia diversidad de disciplinas como la antropología, la sociología, la psicología y la lingüística, entre otras. Desde una aproximación fundamentalmente comunicológica (por lo tanto, inherentemente interdisciplinaria), en el presente trabajo propondremos una caracterización del meme en Internet como texto, en función de su empleo como enunciación durante procesos electorales. Para ello, iniciaremos con una revisión de los planteamientos de Richard Dawkins (1976), con el fin de establecer una base para la caracterización del concepto de meme y cuáles son algunas de sus principales variables.

La segunda parte de nuestro marco conceptual tendrá al texto como objeto de la discusión. Como Lotman (1996) sugiere, se trata de una noción de la que se han planteado numerosas definiciones. Revisaremos algunas que parten del cruce entre la semiótica, la lingüística y la hermenéutica, con la intención de identificar categorías que permitan una mayor comprensión de actos comunicativos que tienen lugar en todo entorno social, incluyendo fenómenos que resultan de la mayor pertinencia en la actualidad, como el meme en Internet.

Así, a partir de una aproximación de tipo cualitativo a una muestra no probabilística y no representativa de memes registrados en Facebook y Twitter durante el proceso electoral presidencial en México en 2018, argumentaremos cómo es que el meme en Internet puede ser entendido como un texto, para lo cual nos apoyaremos en ejemplos recopilados durante nuestro periodo de observación. Se trata de un planteamiento exploratorio que pretende abonar a la reflexión sobre actos comunicativos que pueden actualizar la aplicación del concepto de texto, así como a una mayor comprensión de los usos sociales de la tecnología.

\section{Antecedentes}

Una argumentación que plantee que el meme en Internet puede ser considerado como un texto, implica en primer lugar, una revisión de cómo ha sido descrito este fenómeno cultural y cuáles son algunas de sus principales características. En segundo término, abordaremos de forma sumamente acotada qué puede ser entendido como un texto, apoyados en un conjunto de planteamientos pertenecientes a la intersección entre la semiótica, la lingüística y la hermenéutica. 


\section{$2.1 \quad$ El meme en Internet}

Aunque el fenómeno dado por imágenes, videos y otros signos que son ampliamente compartidos en Internet puede aparentar ser relativamente reciente, en realidad se trata de un asunto que, tanto en lo conceptual como en lo empírico, tiene varias décadas de estar siendo trabajado. En 1976, luego de estudiar las modificaciones en los patrones de cantos en varias poblaciones de aves, Dawkins propone la idea de la existencia de unidades culturales que son replicadas y que forman parte de los acervos de comunidades específicas: los memes (DAWKINS, 1976). En los antecedentes es posible rastrear algunas de las primeras consideraciones sobre este asunto hasta por lo menos finales del siglo XIX, con las Leyes de la Imitación de Gabriel Tarde (TARDE, 1903). La idea de que existen unidades culturales replicables ha sido explorada desde finales de la década de 1960, a partir de conceptos como mnemotipo, idene, sociogen, culturgen, y tipo cultural (WILSON, 1998). No obstante lo anterior, el término propuesto por Dawkins (que se deriva del griego mimos, que significa lo mismo), es el más frecuentemente citado en las referencias especializadas.

Es importante destacar que el planteamiento de Dawkins ofrece un nombre a un fenómeno que, evidentemente, existe por lo menos desde los orígenes de la sociedad. Desde esta perspectiva, los memes no se limitan a fenómenos digitales, sino que pueden ser identificados en una amplia variedad de artefactos y patrones culturales, por ejemplo, en la serie de pasos que se siguen en un baile de salón, en los cánticos de apoyo a un equipo deportivo, así como en toda clase de signos visuales que son imitados y compartidos. Algunos autores del ala más radical de la memética, incluso han sugerido que el lenguaje y toda la cultura puede ser entendida como un conjunto de memes (FLINN, 1997). Como suele ocurrir, esta noción y sus alcances explicativos han sido objeto de amplias discusiones académicas, dando lugar a posturas contrarias (BENÍTEZ, 2001; MCGRATH, 2013), en especial, por la analogía con los virus que Dawkins emplea para presentar su explicación. Al contrario de lo que este autor sugiere, desde nuestra perspectiva consideramos que los sujetos son capaces de ejercer una capacidad de agencia, es decir, los memes no simplemente saltan de una mente a otra, sino que su contingente propagación es el resultado de decisiones más o menos conscientes.

Más allá de estos debates, consideramos que la propuesta de Dawkins permite una descripción del fenómeno que en la actualidad es conocido como meme en Internet. Sin asumir del todo algunas de sus líneas de pensamiento, reconocemos que este autor provee una serie de categorías que pueden ser aplicadas en la realidad social con toda puntualidad: fidelidad, fecundidad y longevidad (DAWKINS, 1976), a las que Da Cunha (2007) agrega una más: alcance (ver Tabla 1). 
Tabla 1: Taxonomía de memes.

\begin{tabular}{|c|c|}
\hline 1. Fidelidad & + \\
\hline $\begin{array}{l}\text { Metamórficos } \\
\text { Altos índices de mutación y de } \\
\text { recombinación }\end{array}$ & $\begin{array}{r}\text { Replicadores } \\
\text { Presentan una reducida variación y una alta } \\
\text { fidelidad con respecto al original }\end{array}$ \\
\hline $\begin{array}{l}\text { 2. Longevidad } \\
\text { Volátiles } \\
\text { Tienen un corto periodo de } \\
\text { propagación }\end{array}$ & $\begin{array}{r}\text { Persistentes } \\
\text { Son replicados durante un tiempo } \\
\text { considerable }\end{array}$ \\
\hline $\begin{array}{l}\text { 3. Fecundidad } \\
\text { Fecundos } \\
\text { Lenta propagación }\end{array}$ & $\begin{array}{r}\text { Epidémicos } \\
\text { Se expanden de manera muy amplia y } \\
\text { muy veloz }\end{array}$ \\
\hline $\begin{array}{l}\text { 4. Alcance } \\
\text { Locales } \\
\text { Áreas geográficas limitadas }\end{array}$ & $\begin{array}{r}\text { Globales } \\
\text { Usados en muy variados contextos y espacios }\end{array}$ \\
\hline
\end{tabular}

Fuente: (DA CUNHA, 2007).

Además de la clasificación anterior, existen algunos tipos de memes que consideramos oportuno referir, como los holomemes y memeplexes. Un holomeme es definido como el repertorio cultural completo de las variaciones que presenta un meme determinado, incluyendo aquellas formas latentes o aún no expresadas (DURHAM, 1991); mientras que los memeplexes son aquellos que están integrados por otros memes (DAWKINS, 1976). Un ejemplo de holomeme surgido durante el proceso electoral observado, estuvo dado por una supuesta similitud entre las propuestas del candidato López Obrador y las políticas del régimen chavista en Venezuela. Algunas de las enunciaciones resultantes desde este holomeme, se muestran en la Figura 1.

a)

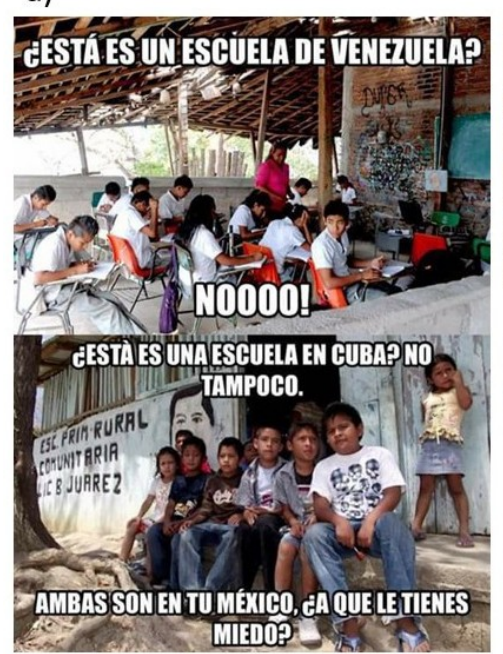

b)

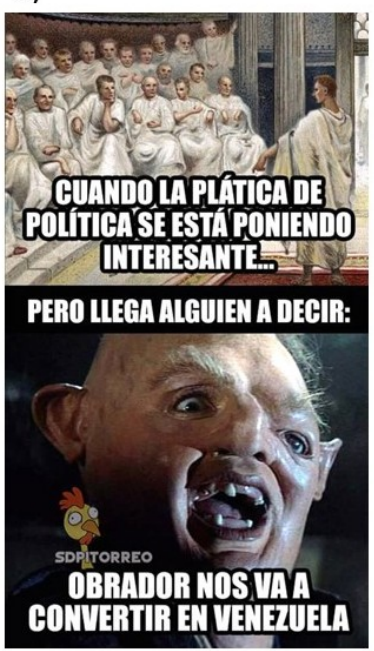

c)

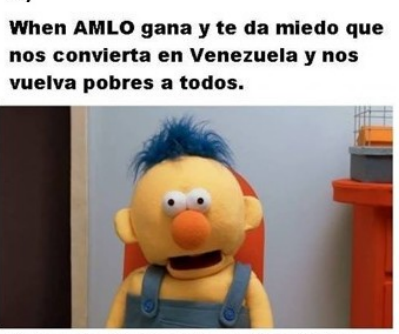

But te acuerdas que no te puedes volver pobre porque solo es pobre el que quiere y tu no quieres.

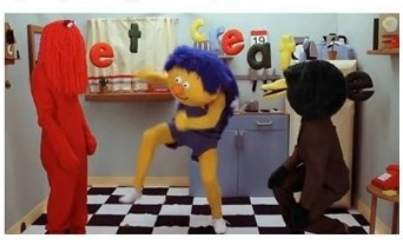

Figura 1: Enunciaciones del holomeme México será como Venezuela ${ }^{1}$. Fuente: Capturas de pantalla en Facebook y Twitter.

1 Este holomeme tuvo su origen en un spot lanzado el 24 de abril de 2018 por el Partido Acción Nacional, en el que se compara a AMLO con Hugo Chávez: https://www.youtube.com/watch?v=gk0Q8c9WA58. 
Una de las características que han sido identificadas en memes que alcanzan altos valores de fecundidad y alcance, tiene que ver con su intertextualidad (ARANGO, 2017), es decir, el empleo de referencias que tienen que ver con situaciones o signos comúnmente identificables en una comunidad específica, y que forman parte de enunciaciones previamente existentes. Aunque el humor suele estar presente en muchos memes, en realidad una parte considerable de su éxito se debe a las apelaciones emocionales que en ellos se plasman: mientras más intensa sea la reacción en este sentido, es mayor la probabilidad de que un meme sea replicado (BURGESS, 2008).

Como hemos sugerido en trabajos anteriores (PÉREZ SALAZAR, 2017), entenderemos al meme en Internet como toda aquella unidad cultural de naturaleza digital que es replicada con diversos grados de fidelidad en los espacios virtuales y que forma parte de un acervo reconocible y utilizado por distintos grupos de usuarios. Lo anterior implica que, debido a su digitalidad, los memes en Internet pueden estar sujetos a diversas acciones de modificación, en función de la disponibilidad de algoritmos y procedimientos capaces de alterar, de manera relativamente simple, los valores numéricos en los que sus signos se encuentran codificados.

A partir de sus formatos, los memes en Internet pueden estar dados por distintos tipos de enunciaciones, donde destacan: cadenas de caracteres (como los hashtags ${ }^{2}$ o trending topics ${ }^{3}$ ), imágenes estáticas o en movimiento (como GIFs animados), que ocasionalmente pueden tener textos incrustados o adyacentes; así como contenidos audiovisuales (videos virales). Sin obviar esta diversidad, para los fines del presente trabajo y por razones metodológicas, centraremos nuestra discusión exclusivamente en aquellos memes dados por imágenes estáticas, en virtud de los siguiente: 1) se trata de uno de sus formatos más frecuentemente utilizados y socialmente reconocido como tal y 2) son el tipo de enunciación que hemos registrado durante nuestro trabajo de campo.

\subsection{El meme-imagen como texto}

El meme en Internet, en tanto imagen estática, implica tomar en consideración una muy amplia discusión sobre este formato generador de sentidos y su condición como texto. Conscientes de la existencia de abordajes postlingüísticos como los realizados por Mitchel (1986) y que implican una discusión sobre la imagen que rebasa los alcances del presente trabajo; nuestro acercamiento más bien estará basado en los planteamientos de autores como Vilches (1984), Lotman (1996), Batjín (1999) y Barthes (1977; 1989), Ricoeur (2001 en GARCÍA, 2011, p. 7) y Zecchetto (2002).

Como sintetiza Aguilar (2008), un texto está dado por cualquier acto de representación simbólica que puede ser leído e interpretado. Desde este punto de vista, el mundo es entendido como un texto, en el cual toda acción, objeto y creación social puede pasar por un proceso de lectura y elaboración de sentido, a partir de un complejo sígnico que le es inherente.

2 Etiquetas socialmente establecidas, generalmente a través de la anteposición del signo \# a una palabra simple, o la concatenación de varias de ellas. Por ejemplo: \#DíaDeElección.

3 Términos, generalmente dados por hashtags, que muestran altas tasas de incidencia y repetición en Twitter. Generalmente asociados a un asunto o tema, son ordenados jerárquicamente en una lista de diez elementos, a partir de áreas geográficas específicas, que pueden ser ciudades, países o términos de tendencia globales. 
Esta conceptualización de Aguilar (2008) condensa propuestas previamente realizadas desde la semiótica. Por ejemplo, para Lotman (1996, p. 54), el texto supone una codificación, una "estructura organizada de signos". Desde Batjín, un texto puede ser entendido como cualquier conjunto coherente de signos (1999, p. 294), que se manifiesta en un enunciado específico. Dicho enunciado, propone este autor, está determinado por dos momentos: la intención y su realización (BATJíN, 1999, p. 295), que es la forma concreta que finalmente adquiere. Desde esta perspectiva, aunque quien realiza la enunciación posee el rol de generador, una vez puesta en circulación, esto implica la existencia de al menos un segundo sujeto que la reproduce, a partir del cual crea otro texto, dentro de una comunicación discursiva que constituye una cadena textual (BATJíN, 1999, p. 295), en la que se construye su sentido.

Dentro de esta cadena, Batjín admite la eventual posibilidad de una nueva representación del texto: la cita. El texto que el lector ${ }^{4}$ reproduce, apela a otros textos y dicho sentido sólo puede tener congruencia con el texto a partir de un código compartido. Esto consiste en "un sistema de signos comprensible para todos" (BATJíN, 1999, p. 296), en el que, bajo el concepto de "lengua del arte" (BATJíN, 1999, p. 296), nos es posible sugerir el empleo de recursos que van más allá de lo estrictamente lingüístico (entendido esto como el estudio de las relaciones entre los elementos dentro del sistema de la lengua: BATJíN, 1999, p. 310). Dada la naturaleza icónica de nuestro objeto de estudio, proponemos que el meme-imagen en Internet puede abarcar también signos de naturaleza visual capaces de generar sentidos compartidos.

En lo que tiene que ver con los referentes a los que se apela, cuando Batjín (1999, p. 305) habla del "texto como reflejo subjetivo de un mundo objetivo", podemos inferir que se trata de la representación que el sujeto enunciante realiza de una parte del contexto que le rodea, y que de alguna manera le es significativo. Así, desde este autor, el enunciado se constituye como un medio que posibilita el conocimiento de la vida de los sujetos sociales. De hecho - apunta Batjín - dado que toda relación social ocurre desde un texto, éste se convierte en la única posibilidad de interacción.

El pensamiento de Barthes (1989) guarda grandes semejanzas con algunas de estas nociones. Para este lingüista y semiólogo francés, el texto es también planteado como un espacio multidimensional, que va mucho más allá que una mera secuencia de signos. Se trata de la conjunción de una indeterminable cantidad de textos previos, de un tejido de citas (BARTHES, 1989, p. 53), de naturaleza absolutamente intertextual (BARTHES, 1989, p. 59). Igual que en Batjín, en este autor, la relación con un texto ocurre a partir de una red de sentidos, experiencias y conexiones que son establecidas con independencia de las intenciones de su creador. Un texto, a diferencia de una obra ${ }^{5}$, no necesariamente lleva la impronta de quien lo ha elaborado, y requiere siempre de la participación activa de aquellos que lo interpretan (BARTHES, 1989, p. 63). En el caso del meme en Internet, dicha participación puede implicar una amplia variedad de acciones, que discutiremos con mayor detalle en la primera parte de nuestros resultados.

Como en Batjín, para Barthes, la relación con todo texto ocurre a partir del signo;

4 Que, desde este planteamiento, se convierte a su vez en coautor de sentido.

5 En su ensayo La muerte del autor, Barthes sugiere una distinción entre una obra y un texto. En la primera, el autor posee un papel central, mientras que en un texto, se establece una relación dialógica en la que la enunciación pasa por un proceso de apropiación y de reelaboración en la que el autor original se diluye. 
por lo que éste (el texto) es radicalmente simbólico y estructurado (BARTHES, 1989, p. 59). Toda relación dialógica de sentido tiene lugar a partir de la enunciación del texto, del cierre sígnico que se construye a partir de una intención que finalmente se concreta. En términos de Zecchetto (2002), en dicha enunciación es posible hablar de textos visuales en los que se combinan elementos o segmentos, y que dan lugar a significaciones generadas a partir de expresiones culturales ubicadas en un contexto, que permite entender los signos y textos que son puestos en circulación. Como plantea Lotman, "el texto representa un dispositivo formado como un sistema de espacios semióticos heterogéneos [...] como generador de sentido, el texto no se presenta ante nosotros como una manifestación de un solo lenguaje [...] El texto es un espacio semiótico en el que interactúan, se interfieren y se autoorganizan jerárquicamente los lenguajes" (LOTMAN, 1996, p. 56).

En relación con la imagen como unidad de sentido, Barthes (1977) plantea que la fotografía constituye un "mensaje sin código" (1977, p. 43) y que, en todo caso, tanto en la publicidad como en las notas informativas, puede encontrarse adyacente a un texto lingüístico que contribuye a la elaboración del sentido. Como podemos apreciar, en este punto hay una posible tensión en la manera en que es posible entender al texto. Si tanto en Batjín (1999) como en Lotman (1996) se encuentra implícita la idea de que un texto supone signos estructurados a partir de un código compartido; en Barthes (1977), la imagen en sí misma parece no contener un código, sino más bien, ser un mero reflejo analógico de la realidad, cuya principal función es mostrarla.

Más allá de la propuesta de Zecchetto (2002) sobre los textos visuales que ya hemos mencionado, en términos del meme-imagen, consideramos que este planteamiento de Barthes supone un rompimiento con la pragmática del signo digital que nos ocupa en este trabajo. Como lo hemos establecido, el meme está dado por unidades culturales que forman parte de los repertorios de comunidades específicas. A partir de acciones sociales reiteradas, de forma arbitraria pero consensuada (igual que en los signos lingüísticos), en ocasiones se asigna un sentido compartido a una unidad visual que no es índice ni señal, sino que se constituye en auténtico signo, que posee un referente, donde, en caso de haber algún texto adyacente, éste se elabora desde dicho sentido, a partir de una situación donde es comunicativamente pertinente su utilización. Esta consideración es cercana a la discusión que se ha hecho de otras expresiones culturales no lingüísticas como un texto, como en el caso de la danza (ACUÑA y ACUÑA, 2011; ALCALÁ, 2018) o la pintura (GARCÍA, 2011).

Donde algunos postulados hechos desde la semiótica parecen no alcanzar a abordar el fenómeno de la imagen en toda su complejidad, la hermenéutica parece plantear una salida más flexible, concretamente a partir de autores como Vilches (1984) y Ricoeur (en GARCÍA, 2011). Para este primero, un texto puede ser entendido como una "unidad sintáctico/semántico/pragmática que viene interpretada en el acto comunicativo mediante la competencia del destinatario" (VILCHES, 1984, p. 35). Para Ricoeur, "la interpretación de la imagen implica también el reconocimiento de la estructura discursiva, no sólo aparente o superficial, sino profunda; es decir, la imagen vista como texto implica analizar cómo opera el soporte material en los elementos diferenciales de la expresión, así como su sintaxis en articulación con tópicos que a su vez llevan a rutas intertextuales, al diálogo" (en GARCÍA, 2011, p. 39). Como es posible observar en estos autores, se trata de nociones que, en esencia, no son tan distintas de las ya observadas en Lotman (1996) 
Batjín (1999) o Barthes (1989): existe la posibilidad de elaborar un sentido a partir de recursos intertextuales que apelan a la capacidad del interpretante para su reconocimiento. Quizá la principal diferencia radique en que desde la hermenéutica, el código se desdibuja como elemento esencial, reiterando que el lector tiene la posibilidad de realizar las conexiones entre los elementos que componen la imagen, con situaciones contextuales (e intertextuales) específicas, que les dan sentido.

En todo caso, en relación con nuestro objeto de estudio, consideramos oportuno ejemplificar la manera en que algunos de estos signos operan como las unidades sintáctico/semántico/pragmática planteadas por Vilches (1984), que pueden ser adaptadas a una gran cantidad de situaciones concretas: las llamadas plantillas (Figura 2).

a)

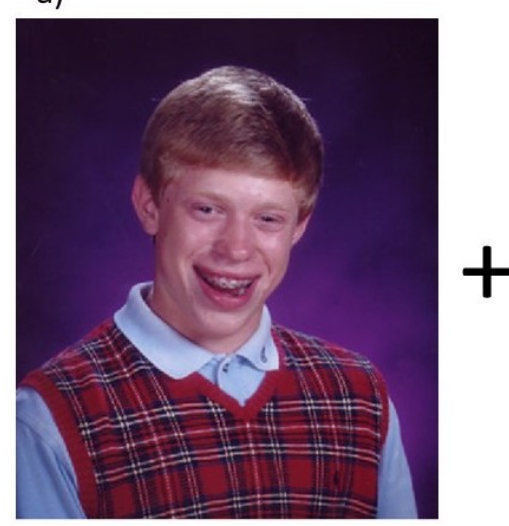

b)

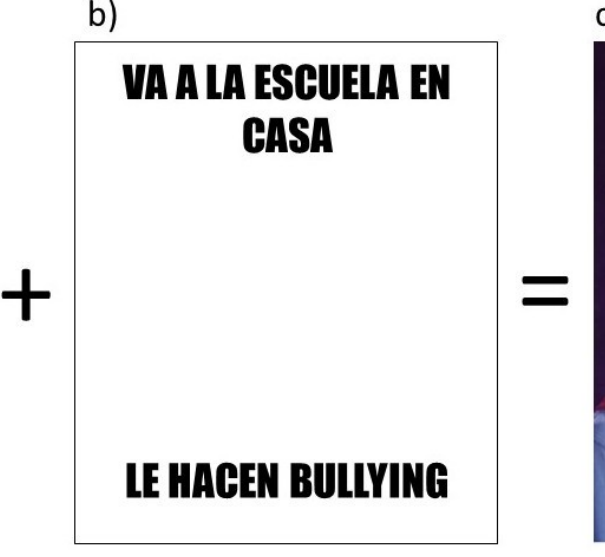

c)

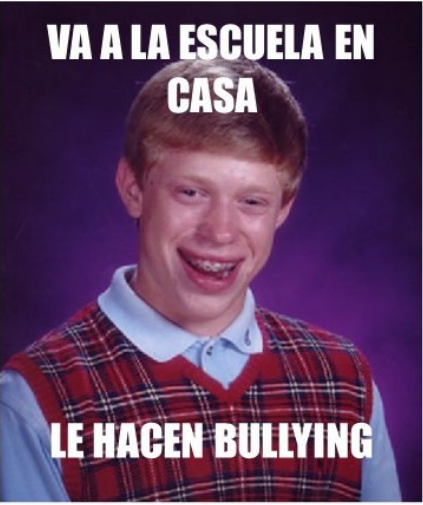

Figura 2: Ejemplo de uso de la plantilla Bad Luck Brian.

Fuente: Elaboración propia a partir de captura de pantalla en livememe.com

La plantilla (inciso a) a partir de la cual ha sido elaborado este meme, tiene un sentido canónico (es decir, más o menos establecido y generalmente aceptado), colectivamente elaborado y reconocible, que en general, alude a una situación de mala fortuna. Cada enunciación específica, cada modificación del meme, ocurre principalmente a partir de los ajustes en los textos incrustados (inciso b). La línea superior usualmente plantea una situación inicial o contextual, que luego presenta un contrapunto en la línea inferior, donde se manifiesta dicha mala suerte. El sentido se construye a partir de la conjunción (inciso c) de estos elementos, que constituyen la estructuración sígnica planteada anteriormente. En memes que no alcanzan a ser constituidos como plantillas, dicho sentido se construye más bien a partir de lo planteado por Ricoeur, es decir, desde la posibilidad que posee el interpretante para relacionar los elementos (de cualquier clase) que se encuentren presentes en tal imagen, con su contexto, con asuntos reconocibles y que le son significativos.

De esta manera, no es posible hacer generalizaciones sobre los memes-imagen que son puestos en circulación en Internet. En cada caso será necesario observar las prácticas relacionadas con cada instancia y determinar el uso/interpretación que se esté haciendo de una imagen en particular. En este escenario, dada la velocidad con que se emplean, recirculan y se establecen sentidos; incluso es posible observar el proceso completo que lleve a su establecimiento como plantilla, en cuestión de unos pocos días. 
Esta es una de las características de los actos comunicativos y de sentido que tienen lugar en la virtualidad.

Como hemos planteado en este apartado, el meme-imagen en Internet, puede ser considerado como un texto. En efecto, se trata de enunciaciones dadas a partir de un conjunto coherente y estructurado de signos comprensibles al interior de lo que Maffesoli (1988) denomina comunidades interpretativas; noción que en Gee (2005) se amplía en lo que llama espacios de afinidad, y que pueden ser entendidos como lugares simbólicos, intangibles; que están dados por todos aquellos sujetos que comparten un mismo sentido en relación con un signo determinado, así como este sentido que es más o menos común a ellos. Apoyándonos en la noción de "signo plástico digital" (PÉREZ BARRAGÁN, 2018, p. 54), los memes que circularon a partir del proceso electoral presidencial 2018 en México, pueden ser propuestos no solo como un texto, sino como auténticas enunciaciones cronotópicas, dada su intencionalidad espaciotemporal.

\section{Método}

En el contexto dado por la elección presidencial en México, se hizo un registro no representativo y no probabilístico de memes publicados en Facebook y Twitter desde el 13 de diciembre de 2017 (fecha límite para el registro de precandidaturas), hasta el 1 de julio de 2018 (día de la elección). Los criterios de registro estuvieron dados a partir de la notoriedad de los principales asuntos específicos relacionados con el proceso electoral, que dieran lugar a memes observables públicamente en dichas plataformas sociodigitales. Tal notoriedad se estableció a partir del posicionamiento de trending topics en Twitter, así como del uso de herramientas como Google Trends; además de su replicación en la esfera mediática, a través de la observación de notas periodísticas que hablaran sobre dichos sucesos.

Esto permitió recopilar un total de 900 unidades (memes-imagen), que fueron catalogadas de acuerdo con los candidatos a los que hacían referencia, así como a los ya mencionados acontecimientos destacados a lo largo del periodo de observación, entre los que destacan por la cantidad de memes que fueron generados, los debates ocurridos el 22 de abril, el 20 de mayo y el 12 de junio de 2018.

Los candidatos participantes en esta contienda fueron: Andrés Manuel López Obrador (AMLO), por la Coalición Juntos Haremos Historia, integrada por los partidos Movimiento de Regeneración Nacional (MORENA), Partido del Trabajo (PT) y Partido Encuentro Social (PES); José Antonio Meade Kuribreña, por la Coalición Todos por México, compuesta por el Partido Revolucionario Institucional (PRI), Partido Verde Ecologista de México (PVEM) y Partido Nueva Alianza (PANAL); Ricardo Anaya Cortés, por la Coalición Por México al Frente, en la que se sumaron el Partido Acción Nacional (PAN), el Partido de la Revolución Democrática (PRD) y Movimiento Ciudadano. A estas tres candidaturas en coalición, se sumaron los independientes Jaime Heliodoro Rodríguez Calderón ${ }^{6}$ y Margarita Ester Zavala Gómez del Campo?.

En el siguiente apartado mostraremos la manera en que tales memes-imagen han

6 Alias El Bronco.

7 Quien renunció a su candidatura el 16 de mayo de 2018. 
sido empleados como enunciaciones sobre dicho proceso electoral, a través de una argumentación en la que pretendemos ejemplificar cómo es que tales unidades culturales pueden ser entendidas como textos visuales digitales.

\section{Resultados}

Con base en lo planteado en los antecedentes de este trabajo y desde su dimensión enunciativa, proponemos al meme-imagen en Internet como un texto. Sustentamos esta caracterización a partir de las premisas que desarrollaremos enseguida, en las que recurrimos a ejemplos específicos obtenidos durante el periodo de observación antes descrito. Tal planteamiento nos permitirá ilustrar la manera en que el meme fue utilizado en un contexto electoral específico, dando lugar a la ocasional expresión de prácticas políticas, entre las que destacan el apoyo/rechazo a un candidato.

a) El meme posee una dimensión sígnica compleja. En todos los casos podemos hablar de una enunciación que se pone en circulación y que da lugar a distintos procesos de construcción de sentido, dependiendo de los contextos y situaciones específicas en las que ocurran las interacciones a las que pueda dar lugar; donde, como ha sido señalado en los antecedentes, distintos lenguajes interactúan en la producción del sentido.

Durante el periodo de observación se observaron distintos trending topics en Twitter, entre los que destacan: Ya Sabes Quién ${ }^{8}$, Insolting and Onacceptobol ${ }^{9}$ y Meade se $\mathrm{Cae}^{10}$, y que como holomemes dieron lugar a enunciaciones de índole icónica como se muestra en la Figura 3.

8 Este meme sobre el candidato López Obrador tiene su origen en un video publicado por MORENA el 12 de diciembre de 2017 titulado Estaremos mejor con... ya sabes quién, disponible en: https://www.youtube.com/watch?v=3f3loB_rskM

9 El 26 de diciembre de 2017 se publicó un video titulado Él es Ricardo Anaya, conócelo, en la cuenta oficial del candidato (https://www.youtube.com/watch?v= AdR7owzcaw). En éste, se argumentaba que el candidato había defendido a México contra la propuesta estadounidense de levantar un muro fronterizo, y se le mostraba diciendo en inglés: It's insulting and unacceptable, frase que da origen al meme.

10 El 29 de mayo de 2018, el candidato Meade se cae de una silla durante su participación en la Tercera Cumbre Ciudadana, en el Palacio de Minería (Ciudad de México), lo que da lugar a una gran cantidad de memes que hacen referencia a este incidente. 
a)

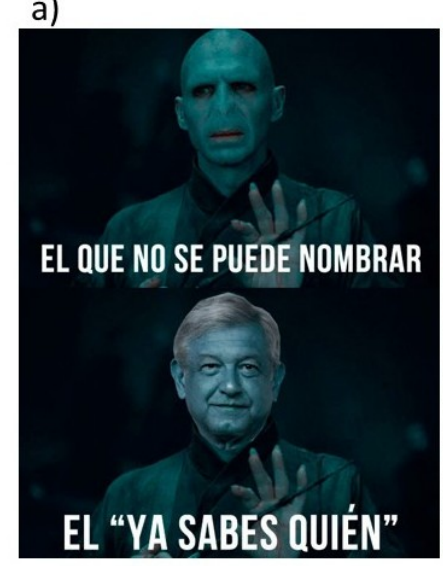

b)

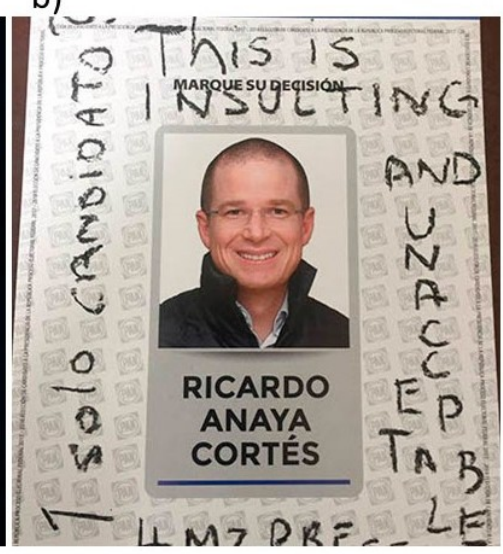

c)

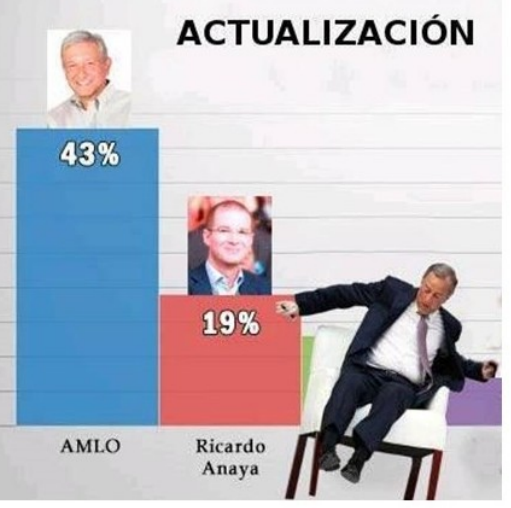

Figura 3: Memes como signos complejos.

Fuente: Composición a partir de capturas de pantalla en Facebook y Twitter.

Aunque en ninguno de estos casos fue posible observar la consolidación de alguna plantilla, la diversidad y estructuración de lenguajes es evidente, dando lugar a combinaciones en las que, como en la imagen señalada con el inciso c, además de fotografías y textos, se encuentran gráficas que corresponden a códigos de representación de datos numéricos, y que en esta enunciación se refieren a una tendencia esgrimida como premisa de debilidad del candidato Meade, y a la que nos referiremos con mayor amplitud más adelante.

b) El meme es intertextual. Como hemos revisado, si en todo texto la intertextualidad es una condición básica, en muchos de los memes en Internet, se trata de un elemento del que parte su sentido. En los ejemplos mostrados en la Figura 3, los holomemes Ya Sabes Quién e Insolting And Onacceptobol, tienen su origen en textos previamente lanzados como parte de las campañas de sus respectivos candidatos: López Obrador y Anaya Cortés. En el caso de la imagen que hemos señalado como con el inciso a, dicho antecedente es mezclado con otro intertexto: la saga de Harry Potter, donde Lord Voldemort, el antagonista, es frecuentemente aludido como El Que No Debe Ser Nombrado. Así, en esta unidad sígnica hay una conjunción que resulta de la cercanía entre dichas enunciaciones previas.

En términos del uso del meme como práctica política, la imagen que hemos señalado con el inciso b en la Figura 3, representa una presunta expresión de molestia ante el hecho de que Anaya Cortés fuera la única alternativa en el proceso interno de la Coalición Por México al Frente para elegir a su candidato, situación que contrasta con el enfoque de la democracia competitiva, que supone la existencia de una oposición y la posibilidad de contrastar opciones a través del voto (COURPASSON, 2007, p. 1005).

c) El meme como cita. Como ya hemos visto en Batjín y Barthes, un texto puede ser elaborado a partir de una cita, es decir, de la reutilización de un enunciado previo, para dar lugar a un nuevo texto. Dada la naturaleza digital del meme en Internet, y como ya lo hemos señalado, los signos que fluyen en este entorno pueden ser modificados con relativa facilidad, por ejemplo, en el caso de memes dados por imágenes estáticas, a partir de editores como Photoshop o GIMP.

En el caso de la imagen señalada con el inciso a en la Figura 4, tiene lugar una intertextualidad que parte de un incidente que se convierte en nota y referente. Sin 
embargo, en este caso, dicho recurso se presenta a partir tanto de la recirculación de la imagen original, en un nuevo contexto (Figura 4, inciso b), como de su modificación a través de una sinécdoque, en la que se selecciona sólo una parte, en este caso, al protagonista del acontecimiento, el candidato Meade Kuribreña (Figura 5).

a)

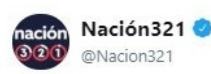

\#FelizMartes ¿Qué título le pondrías a esta foto? 200

Vía: @NelSanMar

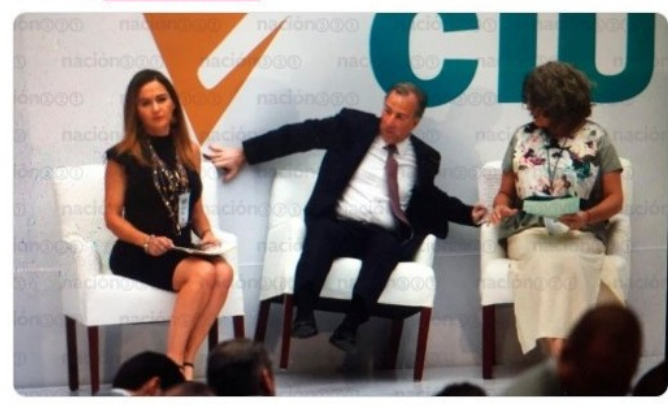

b)

(1) José Antonio Meadell
@JoseAMeadeK

\section{Seguir}

"Cuando me dicen que Nestora va al Senado".

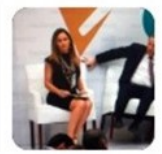

ación3210 @ Nacion321

\#FelizMartes ¿Qué título le pondrías a esta foto? Ât

Vía: @NelSanMar

8:52-29 may. 2018

Figura 4: Meme como cita textual.

Fuente: Composición hecha a partir de las publicaciones en Twitter (de izquierda a derecha): https://twitter.com/Nacion321/status/1001491546846515200 y https://twitter.com/JoseAMeadeK/status/1001495946218430464

a)

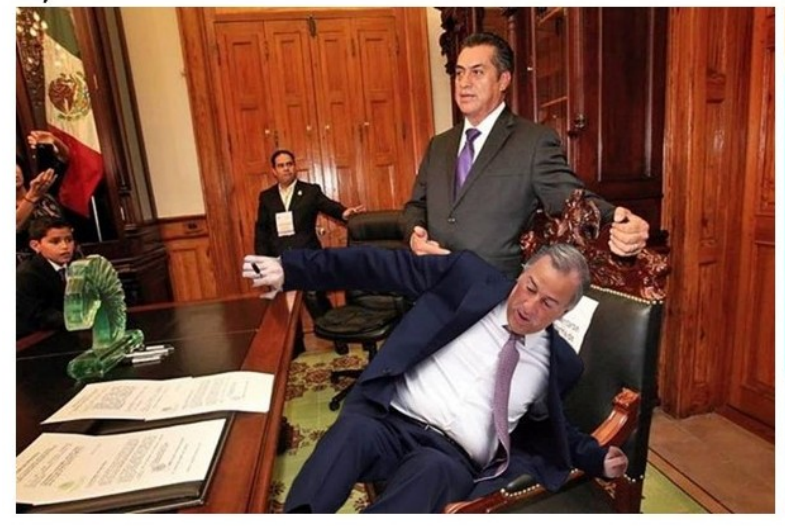

b)

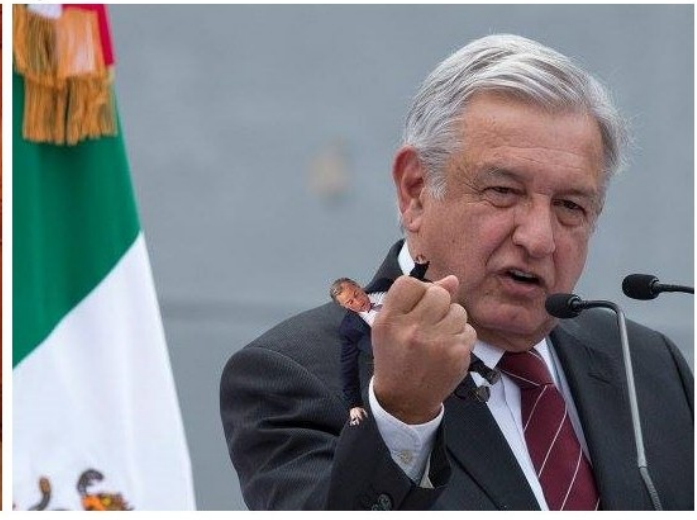

Figura 5: Meme como cita por sinécdoque.

Fuente: Composición a partir de capturas de pantalla en Facebook y Twitter.

Tanto la imagen señalada con el inciso c en la Figura 3, como las dos mostradas en la Figura 5, se erigen como premisas en contra del candidato Meade (es decir, como parte de un discurso). En el primer caso, como ya lo señalamos, su caída física es comparada con una posición desfavorable en las encuestas de intención de voto. En la imagen señalada con el inciso a de la Figura 5, la composición digital sugiere un repliegue a partir 
de la candidatura independiente de Rodríguez Calderón ${ }^{11}$, mientras que en el inciso b, a favor del candidato López Obrador ${ }^{12}$. Desde una perspectiva de participación política, en todas estas imágenes existe la expresión de un posicionamiento, que a través de la proposición de Meade Kuribreña como una opción poco favorecida, se presentan otros candidatos como mejores alternativas; sin importar si esto correspondía con las tendencias de intención de voto reales.

d) El autor del meme. Estrechamente relacionado con lo anterior, la autoría de un meme se convierte en un asunto problemático en los espacios virtuales, sobre todo, en las plataformas sociodigitales que hemos observado. Más allá de las ya mencionadas posibilidades de modificación del signo digital, su mera recirculación implica reflexionar en la naturaleza del discurso digital. En aquellos casos en los que el meme es retomado y vuelto a poner en circulación como parte de las publicaciones de una persona, sin importar si hubo alguna alteración al signo, se trata de una enunciación que puede ser asumida como parte de un sentido que se comparte. En otras palabras, sea esto consciente o no para el usuario, el texto como cita implica la transmisión de un sentido con el que existe una relación y que proyecta una parte del yo ${ }^{13}$ ante los demás. Así, una enunciación determinada, sin importar si es o no de producción propia; por el simple hecho de ser parte de la representación que hacemos de nosotros mismos ante los demás en nuestros muros y líneas de tiempo; se convierte de alguna manera en nuestro texto, y a lo largo del tiempo, en nuestro discurso. El desvanecimiento del autor planteado por Batjín y Barthes, se concreta en función de una apropiación sígnica, de recoger un enunciado y plantearlo como algo propio, aun y cuando se diga de dónde procede el meme en cuestión, o permanezcan rasgos que hagan evidente que se trata de un contenido recompartido (por ejemplo, el nombre del usuario del que lo hemos tomado, en caso de que así lo decidamos, como es posible observar en la Figura 4, inciso b, cuando en la cuenta del candidato Meade se mantiene el origen de la imagen: Nación321).

En este caso, la republicación de Meade añade nuevos elementos sígnicos, en concreto, la auto-broma en la que se hace referencia a Nestora Salgado ${ }^{14}$. La imagen en cuestión había ya alcanzado altos niveles de fecundidad y alcance cuando fue retomada en la cuenta del candidato Meade. Así, el texto de Nación321, se convirtió en el texto de una gran cantidad de usuarios, mostrando muchos de ellos, diversas derivaciones en las que el sentido que se construyó socialmente, era resonante con la desventaja de este candidato mostrada en los estudios de opinión levantados en ese contexto.

Otra posibilidad relativa a la preservación de la autoría de un meme-imagen, se encuentra ejemplificada en el inciso b de la Figura 1. Dentro de la composición, es posible

11 Situación que en ningún momento coincidió con las tendencias medidas a través de encuestas.

12 A diferencia del caso anterior, el candidato López Obrador se mantuvo a la cabeza de las preferencias durante todo el periodo de observación, según las encuestas de intención de voto publicadas en los medios informativos mexicanos.

13 Traducción del self de Mead (2009). En otros autores esto es llamado mi mismo.

14 Activista guerrerense acusada de secuestro, a raíz de su participación en la detención extrajudicial de una persona acusada de robo. Esta detención ocurrió como parte de las acciones realizadas por autodefensas en el estado mexicano de Guerrero, de las que Salgado era dirigente. A pesar de haber sido liberada, el candidato Meade la señaló como secuestradora, como parte de una estrategia de descrédito contra candidatos de MORENA, en una falacia de tipo tu quoque contra López Obrador, durante el debate ocurrido el 20 de mayo de 2018. 
observar una caricatura de un pollo, junto a los caracteres SDPITORREO ${ }^{15}$. Este recurso es conocido como marca de agua, y es empleado en una gran cantidad de grupos en Facebook y otras plataformas sociodigitales, para tratar de hacer patente y preservar la autoría de un meme.

e) El meme como reflejo subjetivo del mundo. Los memes en general, pero de manera particularmente clara, aquellos que alcanzamos a registrar durante el proceso electoral mexicano 2018, son claros ejemplos de la posición que asumen quienes los crean, modifican y comparten. Se trata de enunciaciones cuyo sentido alude a un referente que, de alguna manera, resulta significativo para quienes las emplean; cumplen una función de sentido en un espacio y tiempos delimitados: realizar una expresión política en un proceso electoral de tiempo acotado, por lo que sugerimos que se trata de auténticos signos cronotópicos.

\section{Conclusiones}

Los procesos de comunicación y de sentido que tienen lugar en los entornos virtuales, están sujetos a condiciones propias de la digitalidad, que hacen pertinente reflexionar sobre las formas en que es posible entender a los memes-imagen en Internet como textos, desde un acercamiento multidisciplinar. Los rompimientos espaciotemporales que implican entornos sociodigitales como Facebook y Twitter, comparten algunas características importantes con la literatura, ámbito a partir del cual se ha elaborado una parte de la conceptualización sobre el texto en los trabajos que hemos revisado. En ambos casos, existe una mediación en el acto comunicativo, que opera como vehículo para la elaboración del sentido a partir de códigos compartidos. Los signos empleados dan lugar a textos, es decir, a proposiciones que son puestas en circulación, que pueden ser interpretadas, y que son elaboradas en relación con contextos y referentes socialmente reconocibles.

No obstante lo anterior, dicha condición virtual supone algunas diferencias destacables. Todo signo digital, implica un código numérico. Por ejemplo, un memeimagen, está compuesto a partir de unidades de representación mínimas conocidas como pixeles. Cada una de estas porciones que lo integran, responde a una serie de parámetros numéricos que señalan la proporción de los colores primarios que lo establecen, así como la intensidad en la cantidad de luz que es emitida. Todas estas variables se encuentran expresadas en cantidades que, desde la perspectiva de los dispositivos que permiten observar un signo de esta naturaleza, son finalmente convertidos en una serie de ceros y unos, a partir del código binario con que operan tabletas, computadoras, móviles inteligentes o cualquier otro dispositivo que sea empleado para tal efecto. Como lo hemos ya mencionado, gracias a algoritmos disponibles a través de distintos programas y aplicaciones, es posible manipular con relativa facilidad cada uno de estos elementos que componen un texto visual digital. Al leer una obra literaria en un medio impreso (o incluso en un dispositivo electrónico como

15 Página en Facebook en la que se publican memes y otros contenidos, desde la sátira política (https://www.facebook.com/SDPitorreo/). En términos de lo que ha sido planteado por Batjín sobre la cita, el nombre es en sí mismo un signo que corresponde a esta categoría y que resulta de la parodia de un sitio electrónico de tipo informativo llamado SDP Noticias. 
Kindle), hay un cierre sígnico prácticamente absoluto. Si bien un lector puede hacer anotaciones al margen, subrayar, o incluso mutilar o destruir completamente un libro; el texto como medio es en esencia inalterable una vez publicado. Desde los planteamientos de Batjín y Barthes que hemos revisado, ciertamente dicho texto da lugar a complejos procesos de relación intersubjetiva, de manera que el sentido que se elabora alude a aspectos que son inherentes tanto al lector como a los enunciados a los que se enfrenta desde una propuesta sígnica. $Y$ aunque un texto de esta naturaleza puede ser citado y reelaborado; su enunciación tiende a permanecer relativamente estable.

En los memes-imagen que hemos descrito, la relación que se establece con el texto es distinta. Por un lado, su circulación se potencia gracias a las características sociotécnicas de plataformas como Facebook y Twitter, tanto en velocidad como en alcance. Redistribuir un meme, supone para el usuario acciones tan simples como activar un botón de compartir. En muy poco tiempo, es posible que un texto de esta clase llegue a una gran cantidad de personas, en función de las estructuras reticulares y sociorrelacionales que se encuentren involucradas. Aspectos como la fidelidad, longevidad, fecundidad y alcance pueden ser descritos y analizados a partir de unidades de sentido que, como todo texto, son en última instancia, un reflejo subjetivo del mundo; una enunciación que proyecta una manera específica en que se expresa la realidad. Delimitado a una unidad sígnica discreta, modificable y fácilmente compartible; el memeimagen digital contribuye a una representación de situaciones compartidas que son socialmente relevantes, como ocurre en los procesos electorales a partir de los cuales es posible cambiar la trayectoria de una nación.

Las problemáticas conceptuales implícitas en los textos visuales digitales que hemos presentado son complejas, como lo son también las relaciones entre los lenguajes y elementos significantes que están presentes a su interior. Los memes que hemos analizado no corresponden del todo al campo de los estudios visuales, dado que con mucha frecuencia incluyen signos lingüísticos imbricados en el sentido mismo del meme. De igual forma, tampoco se trata de textos basados fundamentalmente en aplicaciones de la lengua. Nos encontramos ante signos que en muchas ocasiones se manifiestan en enunciaciones híbridas, a las que es necesario aproximarse desde aquellas perspectivas que resulten pertinentes para su análisis, como la hermenéutica o la semiótica de lo visual.

En relación con su autoría, como hemos visto, una vez que el texto ha sido puesto en circulación, a través de recursos como la cita y/o la intertextualidad, es posible que haya nuevas enunciaciones tanto replicadoras (con relativamente pocas o ninguna modificación), como metamórficas (en las que se observan alteraciones importantes). La dilución del autor que había sido discutida por Batjín y Barthes (y eso, cuando en el meme había indicios de su identidad), frecuentemente ocurre a partir de nuevas reenunciaciones. Sin embargo, en el corpus de análisis recopilado durante el periodo de observación, con mucha frecuencia, tal autoría era anónima. Una gran cantidad de memes compartidos en relación con el proceso electoral, circularon sin que su creador fuese identificable. Este tipo de textos alcanzaron a constituirse en discursos, tanto en sus mismos creadores, como cuando fueron retomados por otros usuarios, en el momento en que, a partir de su resonancia con algún tema o postura ideológica, se convirtieron en parte de la secuencia de enunciaciones que denotaban un determinado ser político.

En el caso de los holomemes, cada nueva composición dio lugar a signos que se 
integraron a un acervo de referentes políticos; ya sea a partir de un candidato que sufría en carne propia los efectos de la fuerza de gravedad como metáfora de su baja aceptación, o elaborando enunciaciones contrahegemónicas relativas a los riesgos sudamericanos de elegir a alguno de sus adversarios. El meme se convierte de esta forma en una posibilidad de participar en una discusión de carácter político, así sea -al menos en apariencia- sumamente superficial; a partir de textos que son tomados de estos repertorios culturales y aplicados en situaciones en las que su sentido es socialmente resonante.

Como seguramente ha sido evidente para el lector, nuestra aproximación ha partido de una visión comunicológica, es decir, resaltando los procesos sociales en los que se comparten sentidos, signos y textos; en alusión a dinámicas de interacción que caracterizan al fenómeno que hemos abordado, donde lo político es una de las múltiples posibilidades en las que el meme es empleado para denunciar, protestar, hacer mofa y con esto, ser parte de actos y momentos en los que se elige a quienes habrán de ejercer el poder. En concordancia con la larga tradición instaurada por el cartón político, los memes representan textos en los que el poder es simbólicamente negociado, así sea como mero acto de catarsis.

\section{Referencias}

AGUILAR, C. Desde el sujeto y el texto. Discursividad argumentada de una relación cualitativa. Revista Zona, núm. 5, p. 60-70, 2008.

ACUÑA, A. y ACUÑA, E. Bases teórico-metodológicas para el estudio semiológico y contextual de la danza folclórica. Gazeta de Antropología, 2011, vol. 27, núm. 2, artículo 28, 2011.

ALCALÁ, V. El cronotopos de la danza o la danza como texto. En Merlos, L. B. (Comp.), Actas del IV Encuentro Platense de Investigadores sobre Cuerpo en las Artes Escénicas y Performáticas, La Plata, Argentina, Investigaciones en Artes Escénicas y Performáticas, 2018.

ARANGO, L. G. Yuxtaposición, intertextualidad y humor en los memes de la Reforma en Telecomunicaciones en México. Revista de Estudios para el Desarrollo Social de la Comunicación, núm. 15, p. 304-331, 2017.

BATJíN, M. M. Estética de la creación verbal, 10a edición, México, Siglo XXI Editores, 1999.

BARTHES, R. Image-Music-Text. Londres, Inglaterra, Fontana Press, 1977.

BARTHES, R. The Rustle of Language, Los Ángeles, California, University of California Press, 1989.

BENÍTEZ, L. Memetics: a dangerous idea. Interciencia, 26 (1), p. 29-31, 2001. 
BURGESS, J. All your chocolate rain are belong to us? Viral video, YouTube and the dynamics of participatory culture. En LOVINK, G. y NIEDERER, S. (ed.). Video Vortex Reader: responses to YouTube, Amsterdam, Institute of Network Culture, 2008, p. 101109.

COURPASSON, D. Democracy and organizations. En RITZER, G. (ed.). The Blackwell Encyclopedia of Sociology, Londres, Blackwell Publishing, 2007, p. 1004-1011.

DA CUNHA, R. Memes em weblogs: proposta de uma taxonomia. FAMECOS, núm. 32, p. 23-31, 2007.

DAWKINS, R. The selfish gene, Nueva York, Oxford University Press, 1976.

DURHAM, W. H. Coevolution: Genes, Culture and Human Diversity, Stanford, CA: Stanford University Press, 1991.

FLINN, M. V. Culture and the evolution of social learning. Evolution and Human Behavior, núm. 18, p. 23-67, 1997.

GARCÍA, J. La hermenéutica y las artes visuales. Imaginario Visual, año 2, núm. 1, p. 3643, 2011.

GEE, J. P. Situated language and learning. A critique of traditional schooling, Londres, Routledge, 2005.

LOTMAN, I. M. La semiósfera. I. Semiótica de la cultura y del texto. Madrid: Cátedra, 1996.

MAFFESOLI, M. El tiempo de las tribus. El declive del individualismo en la sociedad de masas, Barcelona, Icaria, 1988.

MCGRATH, A. Dawkin's God. Genes, memes and the meaning of life, Nueva Jersey, John Wiley \& Sons, 2013.

MEAD, G. H. Mind, self, and society: from the standpoint of a social behaviorist, Chicago: University of Chicago Press, 2009.

MITCHEL, W. J. T. Iconology. Image, text, ideology, Chicago, The University of Chicago Press, 1986.

PÉREZ BARRAGÁN, I. El signo plástico digital, En GOUTMAN, A. et al., Más allá de la Matrix. Teoría audiovisual, México, Ed. Ce-Acatl, 2018, p. 54-94.

PÉREZ SALAZAR, G. El meme en Internet. Identidad y usos sociales, México: Fontamara, 2017. 
TARDE, G. The Laws of Imitation, Nueva York, Henry Holt \& Company, 1903.

VILCHES, L. La lectura de la imagen. Barcelona, Paidós, 1984.

WILSON, E. O. Consilience: the Unity of knowledge. Nueva York: Alfred A. Knopf, Inc., 1998.

ZECCHETTO. La danza de los signos. Nociones de semiótica general, Quito, Ecuador, Ediciones Abya-Ayala, 2002.

Recebido em dia 18 de dezembro de 2018.

Aprovado em dia 18 de janeiro de 2019. 